\title{
Role of the SPbPU-FESTO «Synergy» Centre in the Development of Engineering Competences and Skills
}

\author{
V.N. Khokhlovskiy ${ }^{1}$, V.V. Potekhin ${ }^{1}$ and E.M. Razinkina ${ }^{1}$ \\ ${ }^{1}$ Peter the Great St. Petersburg Polytechnic University, 29 Polytechnicheskaya Str., 195251 St. Petersburg, Russia
}

\section{Abstract}

Web and Internet technologies for education of university students and for engineering staff (continuing education) on electrical engineering are considered. The Web and Internet technologies form an important part in modern curricular as a subject for learning as well as a means of organization of education process. A set of specific subjects for students is presented.

Keywords: electrical engineering curriculum, Industrial Internet of Things, communication networks, distribution networks, energy efficiency

Received on 01 December 2017, accepted on 22 February 2018, published on 10 July 2018

Copyright (C) 2018 V.N. Khokhlovskiy et al., licensed to EAI. This is an open access article distributed under the terms of the Creative Commons Attribution licence (http://creativecommons.org/licenses/by/3.0/), which permits unlimited use, distribution and reproduction in any medium so long as the original work is properly cited.

doi: 10.4108/eai.10-7-2018.155045

\section{Introduction}

The last decade has showed quite clear trend: a modern technology in any specific area is the traditional technology plus information technology. This related to electrical engineering education as well. The paper considers how the Higher School of Cyber-Physical and Control Systems at Peter the Great St. Petersburg Polytechnic University moves to solving the task.

\section{Synergy Center}

North-West Russian Regional Intercollegiate Education and Research Centre "SPbPU-Festo" Synergy" at Peter the Great St. Petersburg Polytechnic University was founded in 2014. The Centre includes laboratories:

- Laboratory of intelligent systems for data processing and control systems

- Laboratory of motion control systems for robotics

- Laboratory of complex automation and control

- Laboratory of electronics and electrical drives

- and puts its main task for more efficient use of the intellectual potential and high-tech equipment, as well as a focus of educational programs, improving the efficiency of scientific research in collaboration with leading companies.

The activities aimed at developing and implementing educational programs for engineers. Educational programs of the Centre are based on specific disciplines in the field of control, automation and drive systems, and robotics. As part of the educational programs will be carried out modernization of existing and development of new curricula and programs; preparation of the necessary guidelines and manuals, updating and creation of experimental base and laboratory stands.

Currently, the Centre has laboratory equipment allowing to improve student skills in design of integrated intelligent control systems and management of complex distributed objects, systems and processes in a large flow of information and the lack of predictable control algorithm. The equipment includes:

- 24 places for the development of the skills of designing control systems of industrial objects and technological processes (based on SIMATIC SIEMENS PLC).

- Educational Laboratory Complex FMS500, provided by Festo company

- The Stand of fault-tolerant industrial control system of the upper level 


\section{Peter the Great St. Petersburg Polytechnic University}

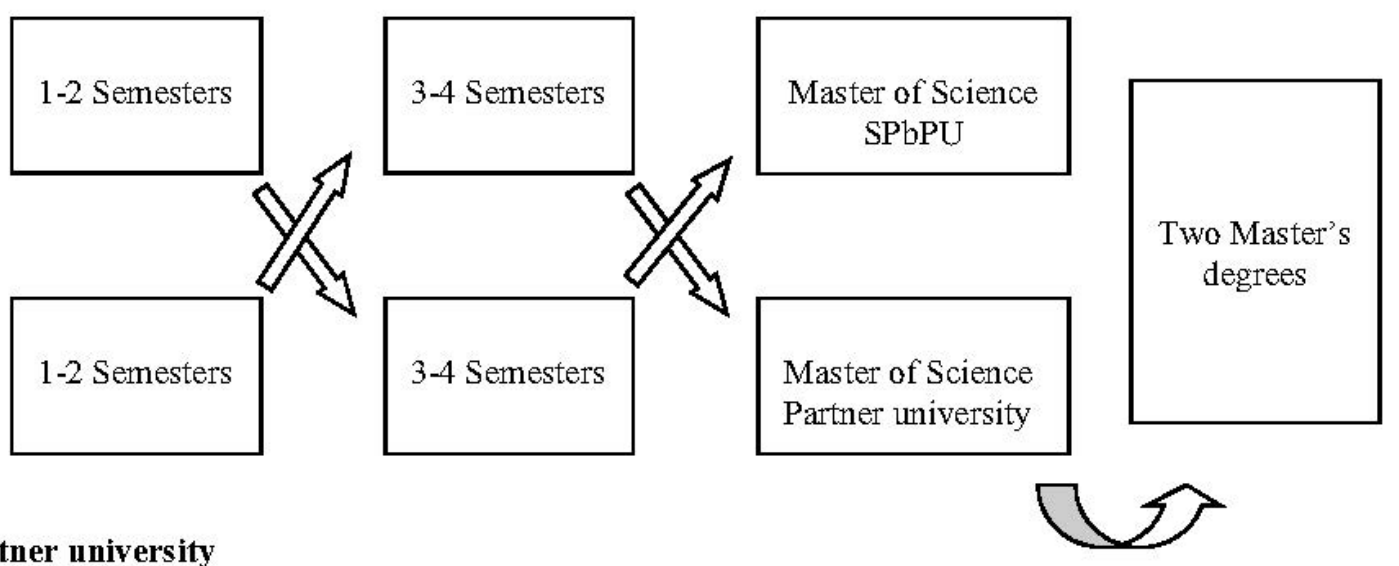

\section{Partner university}

Figure 1. Schedule of educational process in Master double degree program

- The system of distributed digital sensors industrial electronics

- Industrial Monitoring System Siemens SiPLUS CMS

- Hardware-software complex NI Embedded Vision System for GigE Vision

- Hardware-software complex control system based on LabView

- Software LabView Robotics software bundle.

Peter the Great St. Petersburg Polytechnic University has very wide experience in developing and realization of programs in English with such European partner-universities as Leibniz Universität Hannover (Germany), Lappeenranta University of Technology (Finland) and City University London (Great Britain). Approach to realization of double degree programs is shown on the Figure 1. $[1,2,6]$.

According with the schedule of educational program, students enrolled in the program study during the 1 st and 2nd semesters at Peter the Great St. Petersburg State Polytechnic University, and the next two semesters in European partner-universities. Continuation of the study for the second year in partner-university is possible only after successful completion of the first year in Peter the Great St. Petersburg State Polytechnic University. At the end of the second semester of the first-year university provides to the partner academic record of students' results. All kinds of studies are conducted in English, and the curriculum and content of the courses allow them to be fully recognized by the partners $[2,3]$.

Let us consider the Internet and Web communication as a means for training and then - how this experience is proposed to be used for education of electrical engineering students (please see $[4,5,9]$ as well).

\section{Distance Learning Course}

Starting from spring 2015 Peter the Great St. Petersburg Polytechnic University is actively developing distance learning courses on the platform Open Education. One of the courses is "Modern industrial electronics". It's developed basing on laboratories of SPbPU. The main objective of the course is to develop understanding of the structure and purpose of modern industrial electronics in the framework of control systems [7,8,11]. Students study the basic requirements for software and hardware, structures and processes implemented within the functional-logical organization of automated technological processes; master the principles of implementation of the control algorithms and real processes equipment, including control in technical systems of the top level. The course introduces basic components of modern systems industrial electronics:

- $\quad$ subsystem for data acquisition and processing (sensors, various means of measurement);

- $\quad$ actuating elements;

- control devices - industrial controllers;

- channels for data collection, transmission and processing - industrial networks, combines the individual elements into a system;

- SCADA systems, providing interaction with a human operator controlled equipment, and allows to control its operations.

Students acquire the following skills:

- Choose, create and maintain complex software and hardware by computing and information systems and networks;

- Formulate and solve circuit engineering problems associated with the choice of the elements requirements for specified parameters APCS;

- Install, test, test and use hardware and software

- Means of computer information systems and automation systems.

Analysis of the employer's demand for graduates of double degree and university network international 
educational programs in the field of information technology, control systems and automation has shown that graduates can successfully work in research institutes, enterprises, in business, including foreign and joint organizations and companies. Graduates are well prepared to the $\mathrm{PhD}$ programs in Russian and foreign universities.

Eleven Russian universities and Karaganda State Technical University, Kazakhstan, have organized Synergy Centers with International Festo company like the Center at Peter the Great St. Petersburg Polytechnic University. The list of universities-participants of the program can be found on the Festo site in the Internet. All the Centers communicate and propose distance learning courses for students (in Russian). This illustrates how the principle of synergy works: as the Synergy Centers have similar stands didactical materials are shared and joint training programs are delivered by the most recognized professors from various universities - sometimes in local mode, sometimes in distance one.

Experience of joint programs implementation showed that developed materials and techniques can be successfully used in educational programs such as summer and winter schools, research training programs of students, international semesters, etc. This can be the basis for innovative educational programs in the field of information technology, control systems and automation.

\section{Electrical Engineering Courses}

Our goal is to support learning of modern technologies, hardware parts and software tools for energy management and energy monitoring in various industries, infrastructure, civil and residential buildings etc. This includes areas of energy efficiency, complex systems and intellectual energy services based on open network architectures.

In order to be aware and have skills in smart energy technologies students have to learn courses which traditionally correspond to curricular of industrial automation. As Synergy Center is specialized in this field, has laboratories, staff and experience in delivery such courses, the area of education in modern electrical engineering disciplines seems to be resultative and attractive, with the potential of high quality education.

The following training stands are supposed to solve the educational tasks:

- Stands with simplest industrial programming means - so called intellectual relays;

- $\quad$ Stands with programmable logic controllers (PLC);

- $\quad$ Stands with process automation controllers (PAC);

- Smart electric panel;

- Stands with components (power meters, relay protection units etc.) for energy management system and energy monitoring system.

All stands must be connected through serial link and/or Ethernet link and demonstrate two kinds of communication: data exchange (i.e. sending/receiving messages) and remote control (i.e. access to program or diagnose a device).
We consider below the brief description of the courses proposed to satisfy the needs of electrical engineering students in the field of modern communication technologies.

\subsection{Control systems in energy area}

Based on intellectual relays, PLCs or PACs the course is intended to be a basis for digitization in area of energy. The course relates to programming and must use problemspecific languages according to international standard IEC 61131-3, its program model and Ladder language as essential part of the standard. The course must include chapters devoted to design and implementation of a project as well as ones devoted to maintenance of a real-time control system.

\subsection{Communication and web-services for electrical devices and smart panels}

The subjects for study here are modern electrical devices with communication functionality: power meters, relay protection units, insolation control units, circuit breakers, etc. Usually they use a serial protocol like Modbus SL and are connected to a bridge or a gate which in his turn provides communication through Ethernet protocols. The gate can have an option of a web-server. In this case the higher level of a monitoring and control system can use data exchange as well as web-client functionality. At the starting chapters of the course a student must master technologies of industrial communications and widespread protocols as Modbus SL, Modbus TCP/IP, Ethernet IP, IEC 61850 [10] etc. The special attention should be devoted to safety of communication. Thus, the course demonstrates the implementation of ideas of Industrial Internet of Things applied to energy generation, distribution and use.

\subsection{Energy management systems and Energy monitoring systems}

The systems should demonstrate the principle that we can save something if this is measured. The systems are built as modern HMI-tools with regular functionality. This includes access to lower-level field data, advanced graphics, realtime and historic trends, various data presentation (histograms and time series of many different types), alarm processing, report generation, schedules, user administration, possibility to program user tasks, etc. The separate point relates to analysis of gathered data, potentially Big Data. This is an open research topic, and elements of it can be considered as learning tasks for students (regular statistic processing of archived data), and other ones - as a demo approach for new methods (i.e. predictive analytics and machine learning). 


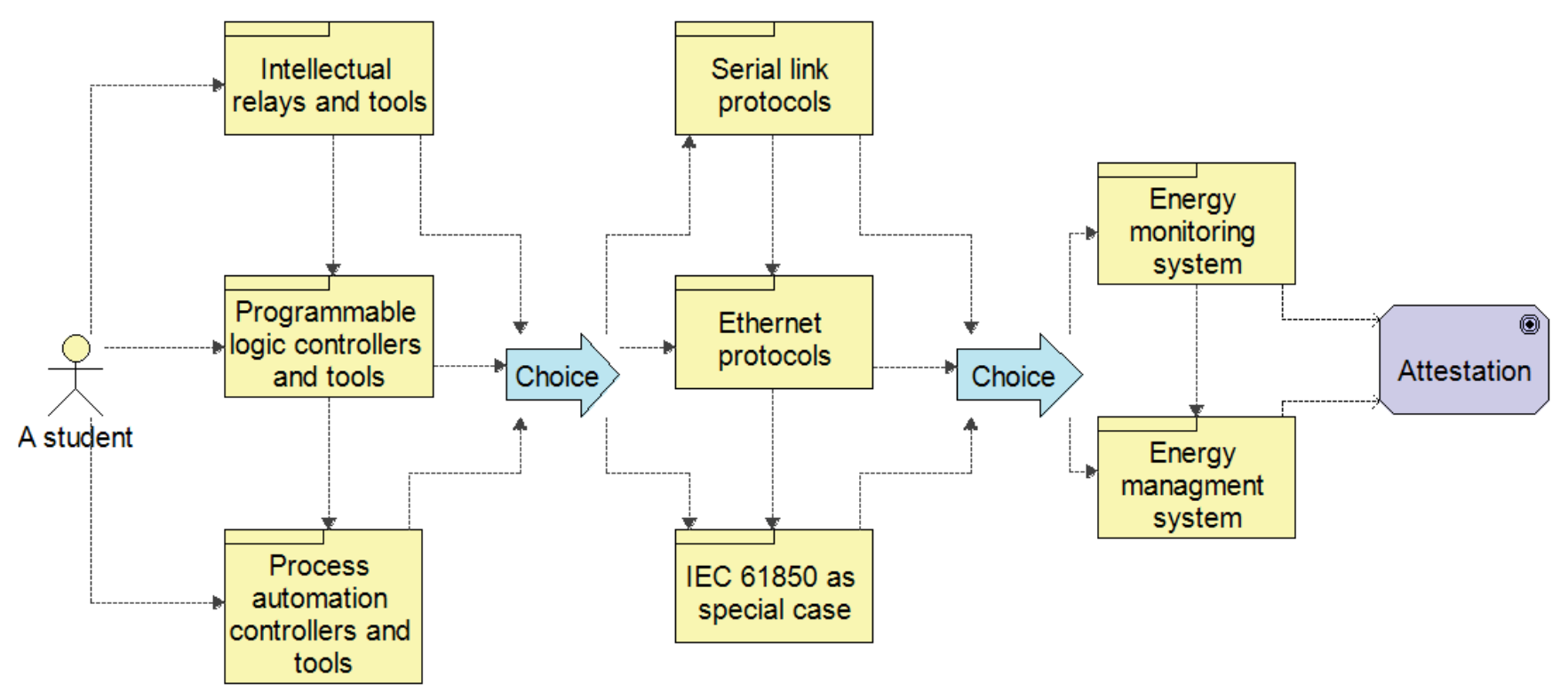

Figure 2. Possible traces for studying courses

Figure 2 shows possible traces for studying courses. We can mention that there is a choice in the starting leftmost position as well. The main direction is from left to right. As more information-saturated courses are positioned at lower level, the arrows are oriented downwards. A student can make a choice and can study one, two or three partitions in each course. The detailed information about content of the courses and organization of the educational process is available from authors on request.

\section{Conclusion}

Synergy Center at Peter the Great St. Petersburg Polytechnic University works in the areas of intelligent systems for data processing and control, motion control systems for robotics, complex automation, electronics and electrical drives. Main efforts have been done for more efficient use of the intellectual potential and high-tech equipment available at the laboratories, particularly for developing new innovative educational programs. The brief description of such a program for electrical engineering students has been presented in the article. The novelty of the educational process relates the fact that electrical engineering students have classes in industrial automation laboratories and must get knowledge and possess skills which are regular and habitual for industrial automation area. Maybe the most important educational result is a psychological one: electrical engineering students are intended not to feel a fear of unknown technical features in special programming languages (like IEC 61131-3), communication protocols, control devices, and SCADA-systems.

\section{Acknowledgements}

The authors thank professor V.V. Titkov, SPbPU and professor M.G. Popov, SPbPU for discussions resulted in clearer understanding of needs for electrical engineering education.

The results described in this article are also planned to be used in the implementation of the project Erasmus+ 573545EPP-1-2016-1-DE-EPPKA2-CBHE-JP APPLE part of which is the developing of a network laboratory ROBOLAB.

\section{References}

[1] POTEKHIN V.V., SHKODYREV V.P., POTEKHINA E.V., SELIVANOVA E.N. Double degree programme in engineering education: practice and prospects. In Proceedings of $41^{\text {st }}$ SEFI Conference, (2013).

[2] SURYGIN A.I., POTEKHINA E.V., POTEKHIN V.V. Curriculum Design Aligned with Russian National and EURACE Standards. Master degree programme in the field information technology and computers. In Proceedings of 40th annual conference SEFI, Thessaloniki, Greece, pp. 372373, (2012).

[3] DUZ I.A., EMELIANOVA O.G. etc. Normative and methodological recommendations on realisation of joint educational programs on the example of Russian-Finnish Cross-Border university (CBU) SPBSPU, St. Petersburg, (2011).

[4] Vyacheslav V. POTEKHIN, Dmitry N. PANTYUKHOV and Dmitrii V. MIKHEEV. Intelligent Control Algorithms in Power Industry. EAI Endorsed Transactions on Energy Web. Volume 3, Issue 11, (2017).

[5] Ekaterina V. POTEKHINA, Elena N. SELIVANOVA ${ }^{1}$, Vyacheslav V. POTEKHIN, Viacheslav P. SHKODYREV. Implementation in Joint International Educational Programs. 
SPbPU's Experience in Festo Technologies. In Proceedings of 26th DAAAM International Symposium on Intelligent Manufacturing and Automation, pp. 1572 - 1581, (2015).

[6] SHKODYREV V.P., POTEKHINA E.V., BABAKINA N.A., SELIVANOVA E.N. Report on activity № 2.2.3 Development and realisation of educational process in joint international educational programs for Masters SPBSPU, St. Petersburg.

[7] ARSENIEV D.G., KOVALEVSKY V.E., SHKODYREV V.P., POTEKHIN V.V. Multiagent Approach to Creating an Energy Consumption and Distribution System, In Proceedings of the VII International Conference "International Cooperation in Engineering Education," St. Petersburg, Russia, July 2-4 2012, pp. 131-140, (2012).

[8] TURNER, C. J., HUTABARAT, W., OYEKAN, J. AND TIWARI, A. Discrete Event Simulation and Virtual Reality Use in Industry: New Opportunities and Future Trends', In IEEE Transactions on Human-Machine Systems, 46(6), (2016).

[9] Juho MÄKIÖ, Elena MÄKIÖ-MARUSIK, Eugeny YABLOCHNIKOV. On Educating Cyber-Physical Systems in a Global Environment. In Proceedings of the International Multiconference Network Cooperation in Science, Industry and Education (NCSIE), St-Petersburg, Russia, pp.133-140, (2016)

[10] Erkki ANTILA and Reino VIRRANKOSKI. PAC - a MultiVendor Environment Based on IEC 61850. In Proceedings of the International Multiconference Network Cooperation in Science, Industry and Education (NCSIE), St-Petersburg, Russia, pp.21-28, (2016)

[11] Damir Haskovic, Branko Katalinic, Ilija Zec. Support and Learning Functions of the Intelligent Adviser Module. In Proceedings of the International Multiconference "Network Cooperation in Science, Industry and Education (NCSIE)", St-Petersburg, Russia, July 4-6, 2016, pp. 183-189, (2016) 